\title{
THE COMPACTING PROCESS OF THE EN AW 6060 ALLOY
}

\author{
LukÁš DragošEK ${ }^{a}$, RóBert KoČišKo ${ }^{a}$, Andrea KováČOvÁ ${ }^{a}$, \\ RóBert BidulskÝ ${ }^{a, *}$, Milan ŠKROBIAN $^{b}$ \\ ${ }^{a}$ Department of Metal Forming, Faculty of Metallurgy, Technical University of Košice, Vysokoškolská 4, 04200 \\ Košice, Slovakia \\ b Sapa Profily a.s., Na Vartičke 7, 96501 Žiar nad Hronom, Slovakia \\ * corresponding author: robert.bidulsky@tuke.sk
}

\begin{abstract}
This study reports on an investigation of factors affect the process of compacting $\mathrm{Al}$ chips which are used to direct scrap processing through the forward extrusion method. EN AW 6060 chips of different geometry and types were mainly used as the experimental material. The chips were compacted in a die with a vertical channel $(10.3 \mathrm{~mm}$ in diameter). To provide a range of processing conditions, three different weights were selected and compacting was performed under five, different compacting pressures. The movement of the chips within the die during compacting was analysed through numerical simulations using Deform 2D software. Study of the compacting process optimal parameters for increasing the density and enhancing the density distribution were defined. The results from our study clearly show that optimal conditions are obtained when the proportion of $\mathrm{D} / \mathrm{h}$ is $1 / 1.1$. Moreover, it was recognized that in the process of small chips compacting, there was obtained lower density than in the case of large chips.
\end{abstract}

KEYWORDS: compaction; aluminium chips; finite element method; porosity.

\section{INTRODUCTION}

In general, primary aluminium processing is one of the most energy-demanding fields in metal production [1, 2]. Depending on the technology that is applied, 168 GJ or 200 GJ of energy is needed to produce one ton of aluminium, which is 10 times greater than the energy requirement for steel production [2]. $\mathrm{Al}$ products are at present mostly manufactured by gravity or high-pressure casting, by extrusion and also with the use of powder metallurgy (PM) methods. In the final step, it is also necessary to modify the geometrical parameters of the end product through machining. In recent years, chips have become a popular commodity for enhancing the efficiency of recycling process [3]. Re-melting is a well-know method for processing Al scrap [4. Re-melting reduces the energy consumption for the whole process of $\mathrm{Al}$ production, but due to the high affinity of $\mathrm{Al}$ to oxygen, re-melting also leads to significant material losses through the oxidation process in a molten metal [5, 6]. Due to the large specific surface, the material losses can grow in the process of re-melting $\mathrm{Al}$ chips. For small chips, the material losses account for almost $50 \%$ [7, 8]. A solution proposed and designed by Max Stern and patented by him in 1945, was forward extrusion of the chips, performed at an elevated temperature [9]. In 1977, this method was modified and innovated by Sharma and Takahashi [10, 11]. This kind of chip recycling can also be used for steels, for cast iron, for copper and for aluminium alloys 12. The method of forward extrusion of chips involves compacting the chips at ambient temperature, followed by extrusion at an elevated temperature. In the first stage, the chips are mechanically compacted and are then pressed [13]. Within the arrangement of the chips, open porosity emerges which is not fully removed in the second stage of processing. In addition, depending on the degree porosity of the compact, some of the pores are closed. In general, pores which are not able to move to the surface, and therefore remain inside, are influenced by deformation (during processing). They are subjected to great compacting pressure, and this has a negative impact on the mechanical properties of the final product. As the real length of a shaft depends on its density, the porosity of the compact has a significant influence on the quality of the final product (manufacturing line productivity) [14-16]. The first stage of processing is therefore very important. The most widely-used methods for extruding of compacted chips are forward extrusion 17, 18, extrusion through bridge dies [2, 4, 13, and new technologies, such as equal channel angular pressing (ECAP) $20-23$ and friction stir wire extrusion [24].

\section{EXPERIMENTAL MATERIAL AND METHODS}

Two types of chips delivered by SAPA Profily a.s. Slovakia, Žiar nad Hronom, were used as experimental material:

Small chips — which originated from chip cutting operations (drilling, milling, turning). They are spiral in shapes and bow-shapep (Fig. 11). The average dimensions of the chips $(\mathrm{T} \times \mathrm{W} \times \mathrm{L})$ were $0.1 \times 0.2-1 \times 2-10 \mathrm{~mm}$. The effect of mechanical 


\begin{tabular}{ccccccccccc}
\hline & $\mathrm{Si}$ & $\mathrm{Fe}$ & $\mathrm{Cu}$ & $\mathrm{Mn}$ & $\mathrm{Mg}$ & $\mathrm{Cr}$ & $\mathrm{Zn}$ & $\mathrm{Ti}$ & $\mathrm{V}$ & $\mathrm{Co}$ \\
\hline Small chips & 0.44 & 0.3 & 0.03 & 0.04 & $0.35-0.6$ & 0.05 & 0.44 & 0.1 & 0.01 & 0.01 \\
Large chips & 0.45 & 0.3 & 0.17 & 0.3 & 0.33 & 2 & 0.27 & 0.02 & 0.01 & 0.01 \\
\hline
\end{tabular}

TABLE 1. Chemical composition of the small and large chips.

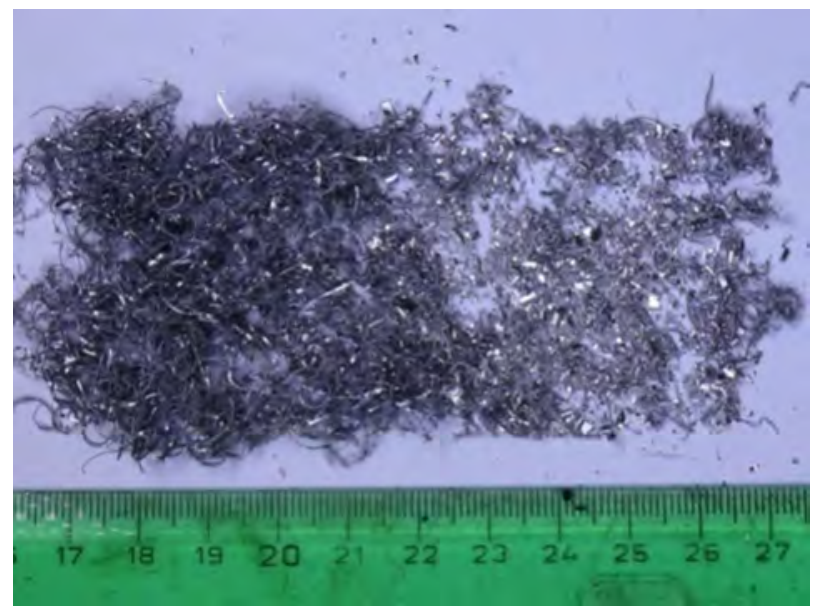

FiguRE 1. Small chips.

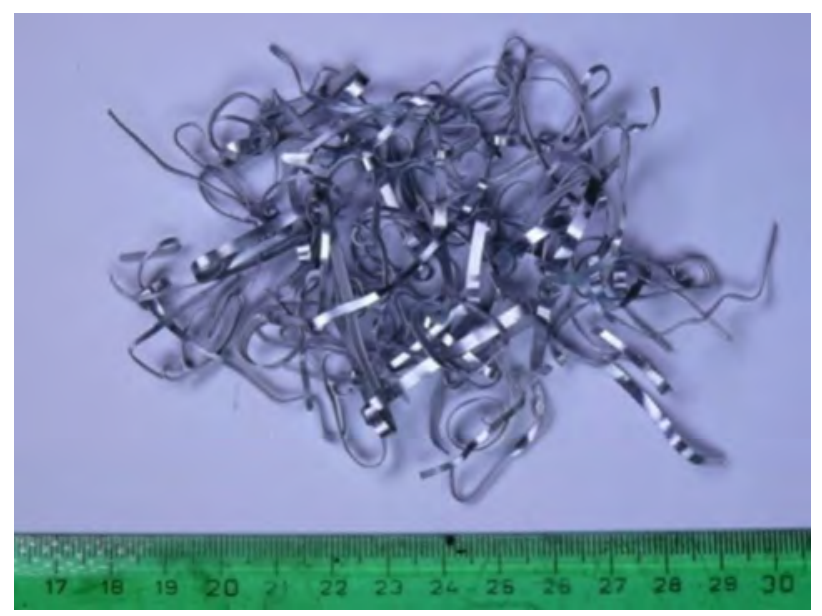

FiguRE 2. Large chips.

strengthening was eliminated after the chips had been cleaned chemically by annealing under the following conditions: $\mathrm{T}=688,15 \mathrm{~K}, \mathrm{t}=9000 \mathrm{~s}$.

Large chips - which originated from a mechanical saw used for cutting shafts at an elevated temperature. The chips were uniform in shape, and consisted of tangled bands (Fig. 2). The average dimensions of the chips $(\mathrm{T} \times \mathrm{W} \times \mathrm{L})$ were $0.5 \times 2.5 \times 20$ $80 \mathrm{~mm}$. The chips were not mechanically strengthened and their surfaces were not polluted.

Both types of chips were analyzed using an optical emission spectrometer. The chemical composition is given in Table 1 (the chemical composition of both types of chips corresponds to EN AW 6060).

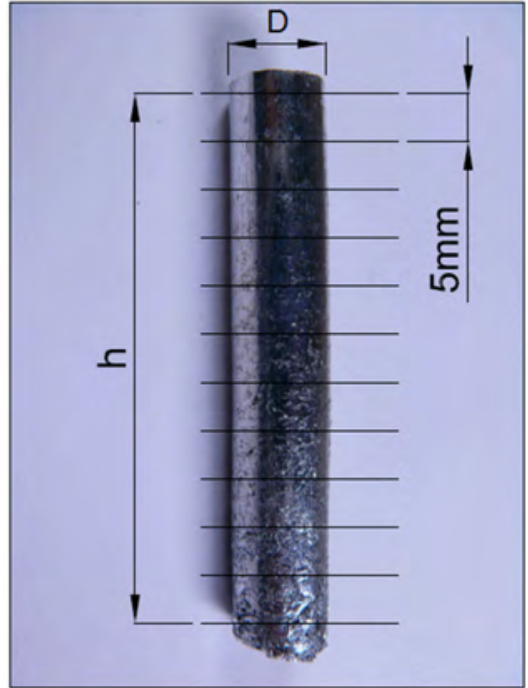

Figure 3. Schematic illustration of the division of the sample.

\subsection{COMPaCting CHIPS}

The two types of chips were compacted under identical conditions (weight 2, 5, $10 \mathrm{~g}$; compacting pressure 300, 400, 500, 600, $700 \mathrm{MPa}$; and speed $0.83 \mathrm{~mm} / \mathrm{s}$ ). To ensure reproducibility of the measurement, each experimental measurement was repeated 3 times. For the compacting process, we used a die with a round, vertical channel $10.3 \mathrm{~mm}$ in diameter and $250 \mathrm{~mm}$ in height. To determine the porosity of the compacts, the density of both types of chips was established to $0.0027 \mathrm{~g} / \mathrm{mm}^{3}$ (according to the chemical composition). The average porosity was calculated using the followin formula $[22,23,24]$, and then the reciprocal density was estimated:

$$
P=\frac{\rho_{\text {chips }}-\rho_{\text {specimens }}}{\rho_{\text {chips }}} \cdot 100 \%
$$

where $P$ is the porosity of compacted samples; $\rho_{\text {chips }}$ is the density of chips; and $\rho_{\text {specimens }}$ is the density of compacted specimens.

\subsection{Density Distribution ACROSS THE COMPACT HEIGHT}

To distinguish the density distribution across the height of the sample, each sample was divided into $5 \mathrm{~mm}$ segments (see Fig. 3). The density distribution was determined for each sample weight, compacted from large chips under pressure at $300 \mathrm{MPa}$. 


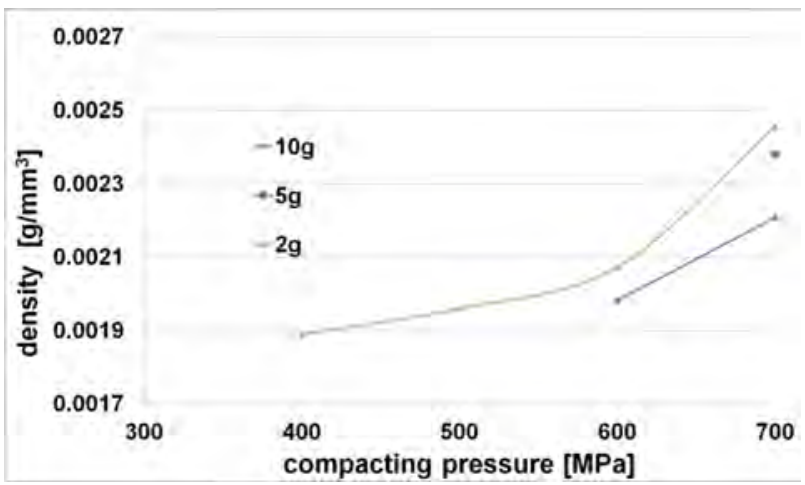

Figure 4. Density vs. compacting pressure - the small chips.

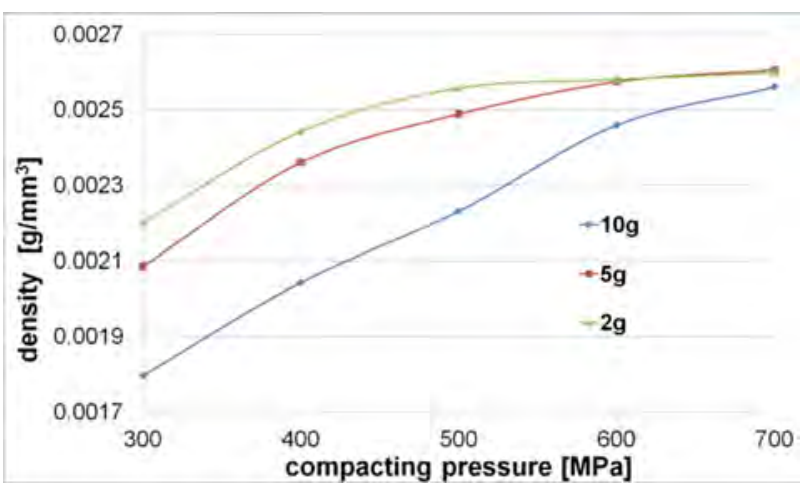

Figure 5. Density vs. compacting pressure - the large chips.

\subsection{Material FLOW DURING COMPACTING}

The material flow in the die during the compacting process was analysed by mathematical simulations in Deform 2D software. The simulation was constructed as the compacting process of a porous material, with the density determined from the height and the weight of the chips. The simulation conditions correspond to the real compacting conditions, i.e., the weight of a sample was $10 \mathrm{~g}$ (large chips) within the simulation. We used a material from the Deform database with similar mechanical properties to those of the experimental material. The STOP criterion for the simulation was the distance (or the final length of the compact).

\section{Results AND Discussion}

Figures 4 and 5 provide graphical illustrations of the density and the compacting pressures of the samples. Figures 4 and 5 show that the large chips provide greater density than the small chips under the same compacting pressure. For explanaition for this can be that the large specific surface and the suspension of the small chips cause the samples to break during handling. It is also seen (Fig. (4) that the density increases as the compacting pressure grows. However, there are some particular cases when growth in pressure does not have a significant influence on the final density of the compact [?].

\begin{tabular}{cc}
\hline Weight & Ratio of $D / h$ \\
\hline $10 \mathrm{~g}$ & $1 / 5$ \\
$5 \mathrm{~g}$ & $1 / 2.5$ \\
$2 \mathrm{~g}$ & $1 / 1.1$ \\
\hline
\end{tabular}

TABLE 2. The ratio of the diameter to the height in the compact.

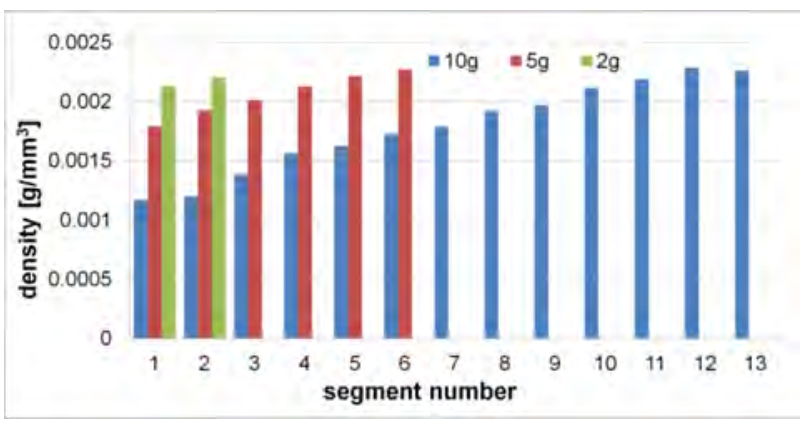

FiguRE 6. Density distribution across the height of the sample.

The experimental studies show that the density decreases as the weight of the sample increases (there is an increase in the ratio of the diameter to the height in the sample) in both cases (small chips vs. large chips). The ratio of the cross-section of he sample to the height (Table 2) has a significant impact on the density distribution across the height of the compact.

Due to the direction from the piston to the lower part of the die, the density declines in all weight conditions (see the graphical illustrations in Fig. 6). The most significant in the density distribution was observed when the sample weighed had $10 \mathrm{~g}$.

The decrease in density (in the direction of the bottom part of the shaft) is caused by the difference in the vectorial movement of the chips in particular parts inside the die during compaction (Fig. 7). In general, the most significant vectorial movement of the chips is assumed to be directly below the piston. It is therefore, easier to carry out processes such as rearranging, pressing and deforming the chips in these parts than in other parts.

In general, increasing density of the compact under the piston leads to a growth in the radial pressure and in the friction area (resulting in enhanced friction at the surface of the die). The next forward movement of the piston in the compacting direction gradually spreads the region with higher density, the contact surface of the shaft and the die, which finally enhances of the friction on die walls of the die. In the compacting process of $5 \mathrm{~g}$ and $10 \mathrm{~g}$ samples made from small chips, we observed an increase in the friction force above the value of the compacting force, after which the material inside the die broke. It was later observed that the samples in the die began to break at one third of their height. These samples were not suitable for a study of the density distribution (not included in Fig. 4). To ensure sufficient compacting 


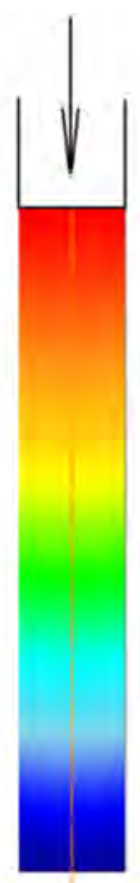

Velocity $(\mathrm{mm} / \mathrm{sec})$ 0.830

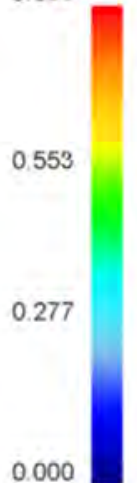

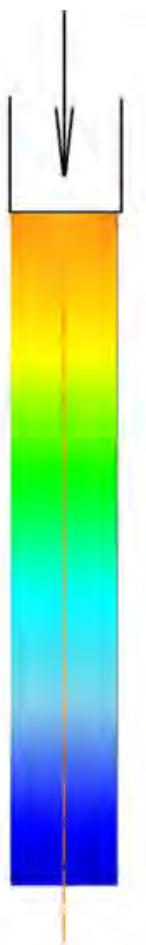

FiguRE 7. Numerical simulation of the compacting process on a $10 \mathrm{~g}$ sample under $300 \mathrm{MPa}$.

efficiency and, at the same time, the best density distribution, it is preferable to compact the chips into shafts with a $\mathrm{D} / \mathrm{h}$ ratio of $1 / 1.1$. A high ratio of $\mathrm{D} / \mathrm{h}$ can be obtained by putting the chips gradually into the layers. However, this increases the friction forces, resulting in breakage when the shaft is pressed. The same phenomenon is recognized when the Al cover is compacted. Another option is to use a two-sided compaction method.

\section{Conclusions}

(1.) The dependence of the density on the amount of compacting pressure is influenced by the size and the geometry of the chips. It is therefore, not possible to specify a general optimal value for the compacting pressure (for all types of chips).

(2.) At the same time, the size and the geometry of the chips has a significant influence on the consistency of the compact while it is being handled. Samples compacted from small chips under all considered pressure conditions (300, 400, 500, 600, $700 \mathrm{MPa})$ were brittle.

(3.) If the $\mathrm{D} / \mathrm{h}$ ratio drops, the density increases and there is improved uniformity of the density distribution across the height of the shaft. The best density distribution was observed when the $\mathrm{D} / \mathrm{h}$ ratio was $1 / 1.1$.

(4.) Due to non-uniformity in the vectorial movement of the chips, it is preferable to process shafts with the $\mathrm{D} / \mathrm{h}$ ratio higher than $1 / 2,5$, using a a two-sided compaction method.

\section{ACKNOWLEDGEMENTS}

This work was realized within the frame of the Operational Programs Research and Development: "The centre of competence for industrial research and development in the field of light metals and composites", project code ITMS 26220220154, financially supported by a European Regional Development Fund.

\section{REFERENCES}

[1] J. Gronostajski, A. Matuszak: Journal of Materials Processing Technology, 92-93:35-41, 1999, DOI: 10.1016/S0924-0136(99)00166-1

[2] V. Güley, A. Güzel, A. Jäger, N. Ben Khalifa, A.E. Tekkaya, W.Z. Misiolek: Materials Science and Engineering A, 574:163-175, 2013, DOI: 10.1016/j.msea.2013.03.010

[3] M. Samuel: Journal of Materials Processing Technology, 135(1):117-124, 2003, DOI: 10.1016/S0924-0136(02)01133-0

[4] V. Güley, N. Ben Khalifa, A.E. Tekkaya: International Journal of Material Forming, 3:853-856, 2010, DOI: 10.1007/s12289-010-0904-z C. Schmitz: Handbook of Aluminium Recycling Vulkan-Verlag Gmbh, Essen, Germany, 2006

[5] A.E. Tekkaya et al.: Journal of Materials Processing Technology, 209: 3343-3350, 2009, DOI: 10.1016/j.jmatprotec.2008.07.047

[6] V. Güley, N. Ben Khalifa, A.E. Tekkaya: AIP Conference Proceedings, 1353:1609-1614, 2011, DOI: 10.1063/1.3589746

[7] M. Haase, A.E. Tekkaya: Journal of Materials Processing Technology, 217: 356-367, 2015, DOI: 10.1016/j.jmatprotec.2014.11.028 
[8] M. Stern: Method for treating aluminium or aluminium alloy scrap, US 2391752 A, 25.12.1945

[9] C.S. Sharma, T. Nakagawa, N. Takenaka: Recent developments in the recycling of machining swarfs and blanking scraps by sintering and powder forging, STC F, 26/1/1977, p. 121

[10] T. Takahashi: Development of scrap extrusion reformation and utilization process in Proceedings of 2nd International Aluminum Extrusion Technology Seminar, Band 1, 1977, p. 123-128

[11] J. Gronostajski, H. Marciniak, A. Matuszak: Journal of Materials Processing Technology, 106(1-3):34-39, 2000, DOI: 10.1016/S0924-0136(00)00634-8

[12] R. Kočiško, R. Bidulský, L. Dragošek, M. Škrobian: Acta Metallurgica Slovaca, 20(3):302-308, 2014, DOI: 10.12776/ams.v20i3.366

[13] J. Bidulská et al.: Archives of Metallurgy and Materials, 58(2): 371-375, 2013, DOI:

10.2478/amm-2013-0002

[14] M. Maccarini, R. Bidulsky, M. Actis Grande: Acta Metallurgica Slovaca, 18(2-3):69-75, 2012.

[15] B. Pawlowska: Acta Metallurgica Slovaca, 20(1):28-34, 2014, DOI: 10.12776/ams.v20i1.182

[16] Z.S. Ji, L.H. Wen, X.L. Li: Journal of Materials Processing Technology, 209:2128-2134, 2009, DOI: 10.1016/j.jmatprotec.2008.05.007
[17] M.L. Hu, Z. S. Ji, X. Y. Chen, Q.D. Wang, W.J. Ding: Transactions of Nonferrous Metals Society of China (English Edition), 22:68-73, 2012, DOI: 10.1016/S1003-6326(12)61685-9

[18] M. Haase, N. Ben Khalifa, A.E. Tekkaya, W.Z. Misiolek:Materials Science and Engineering A, 539:194-204, 2012, DOI: 10.1016/j.msea.2012.01.081

[19] W. Tang, A.P. Reynolds: Journal of Materials Processing Technology, 210:2231-2237, 2010, DOI: 10.1016/j.jmatprotec.2010.08.010

[20] Y. Hangai et al.: Materials Transactions, 53(8):15151520, 2012, DOI: 10.2320/matertrans.M2012125

[21] J.B. Fogagnolo, E.M. Ruiz-Navas, M.A. Simón, M.A. Martinez: Journal of Materials Processing Technology, 143-144:792-795, 2003, DOI: 10.1016/S0924-0136(03)00380-7

[22] J. Bidulská et al.: Acta Physica Polonica A, 122(3):553-556, 2012.

[23] J. Bidulská et al.: Chemicke Listy, 105(16):s471-s473, 2011.

[24] R.A. Behnagh, R. Mahdavinejad, A. Yavari, M. Abdollahi, M. Narvan: Metallurgical and Materials Transactions B: Process Metallurgy and Materials Processing Science, 45(4):1484-1489, 2014, DOI: 10.1007/s11663-014-0067-2 